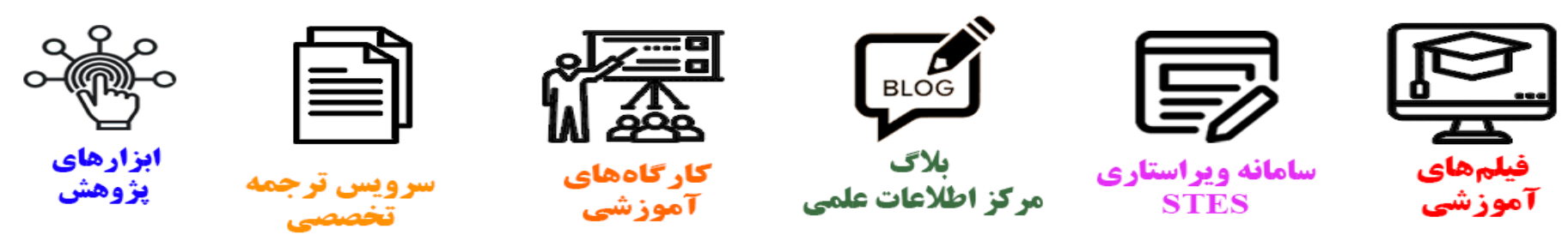

\title{
(c)
}

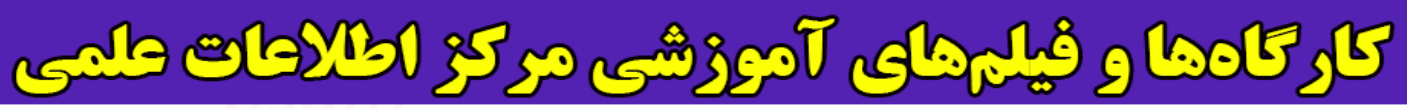
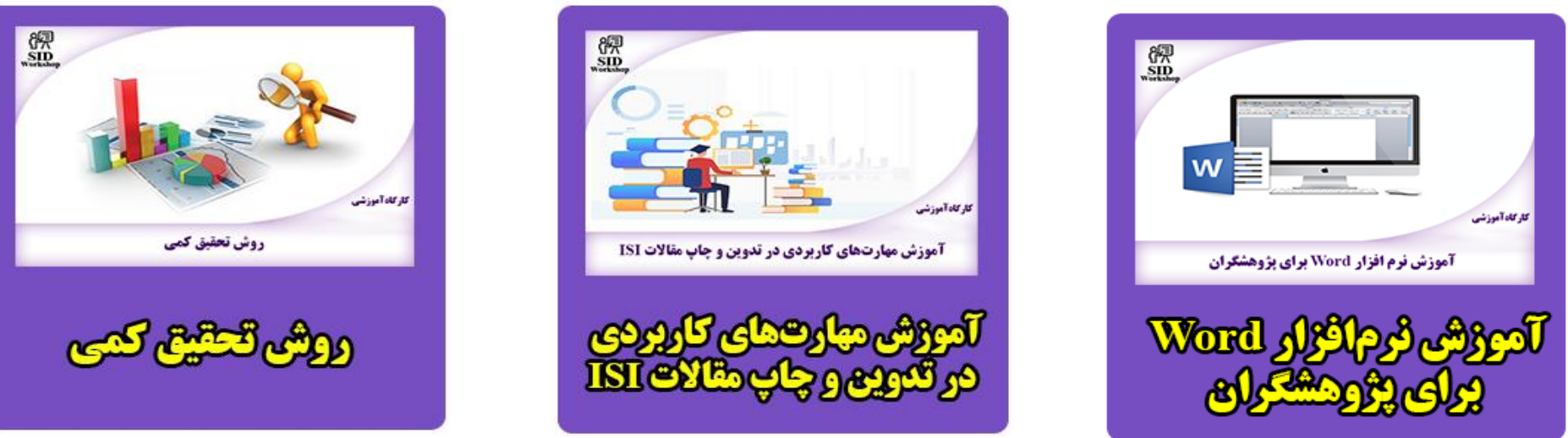


\title{
Technical Note
}

\section{INFLUENCE OF FIBROUS WASTE ADDITION ON THE SHRINKAGE OF MORTARS}

\author{
M. Beddar ${ }^{1}$; L . Belagraa ${ }^{2}$ \\ Geo-material Laboratory, \\ Faculty of Sciences and Engineering Sciences \\ M'sila University, Algeria
}

\begin{abstract}
ABSTRAC
This tentative survey evaluates the influence of fibrous waste (metallic and polypropylene) used on the cracks caused by shrinkage in a mortar prepared from sand of dune (important shrinkage). The achieved tests, to evaluate the free shrinkage or restrained shrinkage, have been reported in this paper. The method described in the article to evaluate the restrained shrinkage consists of using a rigid ring made of steel that is coated by mortar. After hardening, the sample is submitted to conditions required to evaluate the effect of restrained shrinkage .In a given moment, the resistance to the cracking, the number of cracks and the total maximal widths, are measured and compared to what obtained with a plain mortar.
\end{abstract}

Keywords: free shrinkage, restrained shrinkage, cracking strength, fibrous waste, mortar

\section{INTRODUCTION}

The shrinkage is one of the most important physics-chemical phenomena in mortar and implicitly in concrete. This phenomenon which is summarized with a macroscopic deformation deferred occurring in absence of load, appears since the first instants of the life of material and continues during all stages of its hardening.

It is characterized by a consecutive reduction in volume due to the evacuation of humidity. It increases with time tending after many years toward a limit. This depends on several factors, in particular the properties of the material (water and cement ratio, cement and aggregate proportion and the cement content), the ambient conditions (temperature and relative humidity), the degree of maturation and dimensions of the structure.

In practice, the phenomenon of shrinkage is very important. It causes intrinsic tensions (traction outside and compression inside), which can lead to surface cracks. It also causes contraction of structural components (producing tensile stresses and often large cracks) as well as further section deformations creating torsions.

In the literature $(1,2,3)$, one speaks about the shrinkage of mortar or concrete in a fresh state (plastic shrinkage, early or capillary shrinkage) and in a hardened state (drying shrinkage, 
chemical shrinkage carbonation and autogenously shrinkage). These terminologies impose a complexity in the study of this phenomena. But in practice we deal with free shrinkage which relates to all the structures where deformations due to the shrinkage, whatever its origin, can be carried out freely (4), whereas in the case that deformations can be obstructed, the shrinkage is called a restrained shrinkage.

The present research is focused on minimizing the shrinkage phenomenon to avoid the pathological damages generated in the concrete structure and to make it possible to substitute for large crossing cracks by a network of micro-cracks which are less prejudicial to the continuity and the durability of the mortar or concrete material. Hence, the addition of steel fibres and other kind of fibrous waste in the mortar and concrete presents one of our interests in the Géo-materials laboratory of Civil Engineering Dejpartment of M'sila University in order to:

$>$ Minimize the formation of the cracks, and reduce their propagations, their widths and their depths.

$>$ To solve the problem of cracking of mortar or concrete material made of sand of dune (very significant shrinkage) by the incorporation of fibrous waste in this type of materials.

\section{EXPERIMENTALETHOD}

\section{1. Principle}

The experimentation that we implemented consists in carrying out measure tests of free shrinkage on the prismatic test specimen provided with studs at the ends and subjected to the conditions desired (ambient temperature is $20^{\circ} \mathrm{C}$ and $50 \%$ of relative humidity). Measurements were taken using a comparator of precision $0.01 \mathrm{~mm}$.

\section{2. Experimental equipment}

The free shrinkage tests were carried out on prismatic test specimens of dimension $(4 \times 4 \times 16 \mathrm{~cm})$ whose Plexiglas plates were fixed. To improve the contact mortar-plates, the latter have been perforated (in the middle) and studs were fixed. On the first stud (the upper end) will come to butt a comparator, the second (lower end) will be arranged on other plate glued to a motionless frame and ensuring a free rotation of the test specimen submitted for testing (Figure 1). The precision of our measurement comparator is $0.01 \mathrm{~mm}$

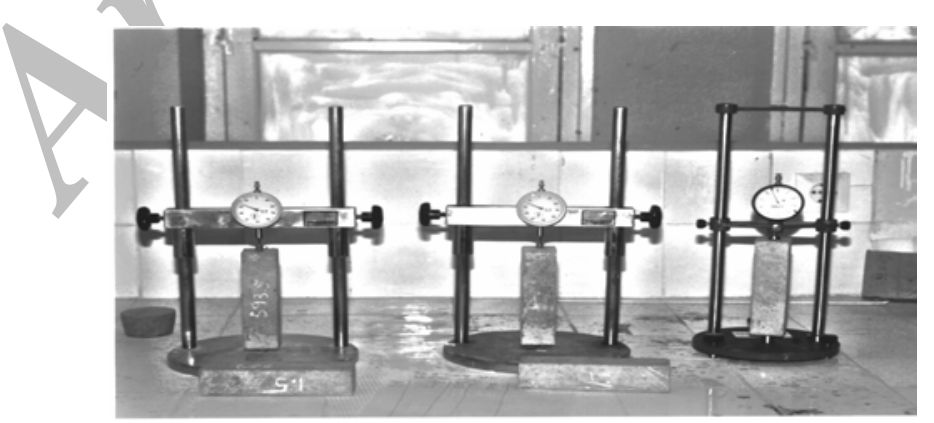

Figure 1 Testing equipment for free shrinkage measurement 
The restrained shrinkage has been evaluated by ring test which consists in using a steel ring (Figure2) of $8 \mathrm{~mm}$ thickness, $143 \mathrm{~mm}$ external diameter, $127 \mathrm{~mm}$ internal diameter and of $44 \mathrm{~mm}$ height, while cementing material ring has an external diameter of $127 \mathrm{~mm}$, internal diameter of $83 \mathrm{~mm}$; and $44 \mathrm{~mm}$ height and $22 \mathrm{~mm}$ thickness ( Figure 3).

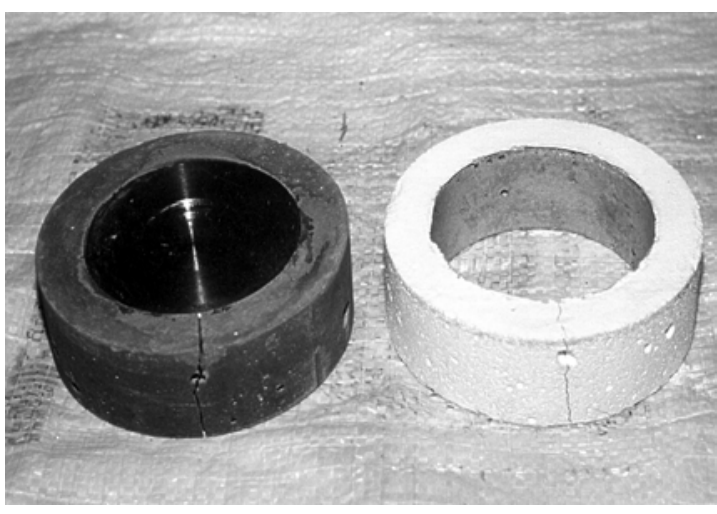

Figure 2 Restrained shrinkage testing the specimen of mortar

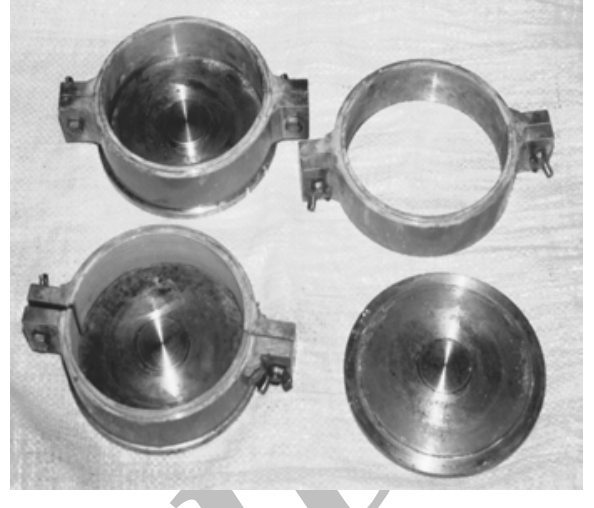

Figure 3 Mould with specimen and demoulded mould (steel ring)

The casting in two layers in this circular mould is carried using a steel shaft. Three rings were made for each test. The specimen prepared were cured at $20^{\circ} \mathrm{C}$ during $24 \pm 1$ hour in a wet conditions.

The apparatus allows a release from the mould and an easy cure of the test specimens. Those specimens subjected to testing with the ring were cured during 24 hours, then were placed in an environment similar to that of free shrinkage until the formation of cracks. For better viewing of cracks and the microscopic cracks propagation, the test specimen subjected to testing with the ring were covered by a white painting.

\section{3. Materials}

Cementitious mortar was employed for these tests using superplasticizer admixture to maintain a constant workability, without varying the quantity of mixing water among the various mixes. Materials used in the tests to evaluate the free and restrained shrinkage are illustrated below :

Sand of dune grade $0 / 5$; Cement CPJ45; Mortar fraction $1 / 3 \quad$ (C: $\mathrm{S}=1: 3)$

$\mathrm{E} / \mathrm{C}=0.58$ ( to have a constant and normal workability)

Fibres : ( fibrous waste metal and polypropylene )

Superplasticizer : $1 \%$

\section{RESULTS AND DISCUSSIONS}

\section{1. Free Shrinkage}

The average curves of the shrinkage according to the time ( days ) are presented on figures 1 and 3. It is noticed, according to the figure 1, that the steel fibrous waste reduces the shrinkage. This reduction is about $16 \%$ compared to a mortar without fibres at 28 days, for a proportion of 
$0.5 \%$ of volume of fibres. But with $1 \%$ of volume of fibres, this reduction is ranged from 11 to $13 \%$. Regarding the experimental tests results, the maximum percentage of fibres to reduce the effect of shrinkage is $1.5 \%$, beyond this percentage of volume of fibres, the presence of fibres in a mortar is not significant.

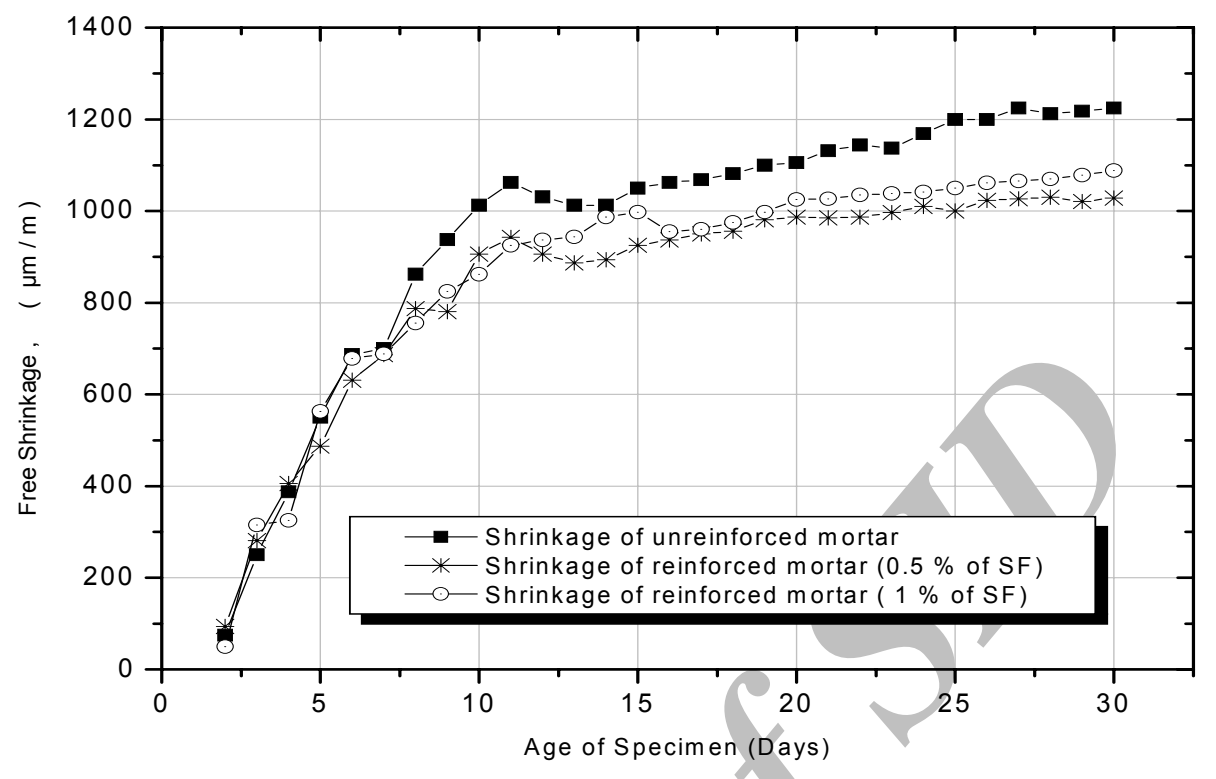

Figure 1. Free shrinkage of a mortar reinforced by steel fibrous waste

These results confirm those already obtained from former studies [4] by using fibres marked under various types, to know that deformations of shrinkage are generally smaller for the fibre reinforced mortars compared to those of the mortar without fibres. This reduction is affected by several parameters like the duration of drying, the shape and the quantity of fibres. The loss of weight of the test specimens was checked. Results are illustrated in figure 2 . It is noted that the loss in weight is more significant for the fibre mortars than for the mortar without fibres (reference). The presence of dispersed fibres increases the size of pores in material as well as volume and decreasing, thus, intensity of the capillary pressures by facilitating the evaporation of water.

On the other hand, according to the experimental tests, the use of fibrous polypropylene waste, with percentage higher than $1 \%$ in volume of fibres, do not give any improvement to the free shrinkage of mortar. This result confirms those obtained by other researchers $[5,6,7]$. It is noted, according to figure 3 , that there is an increase in the shrinkage of approximately $20 \%$ for a content of $1 \%$ in volume of fibres. But this increase reaches the $30 \%$ for a content of $1.5 \%$ in volume of fibres. The increase in the free shrinkage of mortar reinforced with polypropylene fibres may be explained by the fact that these fibres are thin, very flexible and generally coated by layers of fines that causes the increase in free shrinkage by increasing the percentage of fibres. 


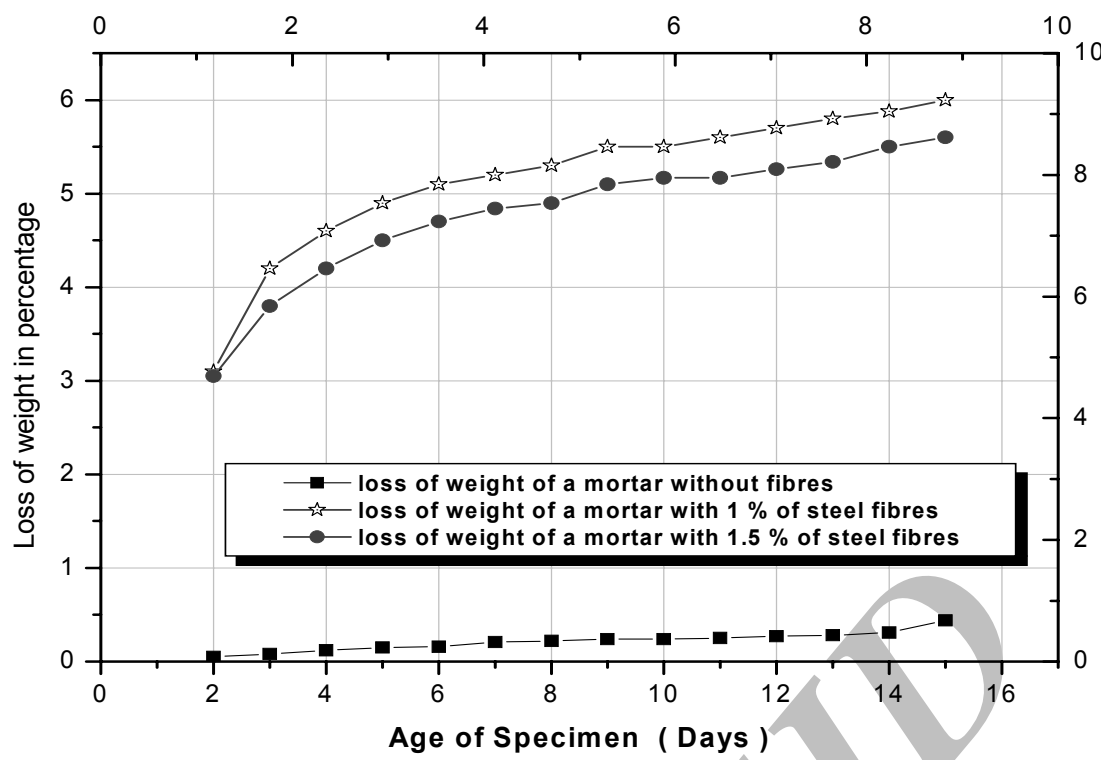

Figure 2. Percentage of loss in weight of a mortar reinforced with fibres $(0,1,1.5 \%)$

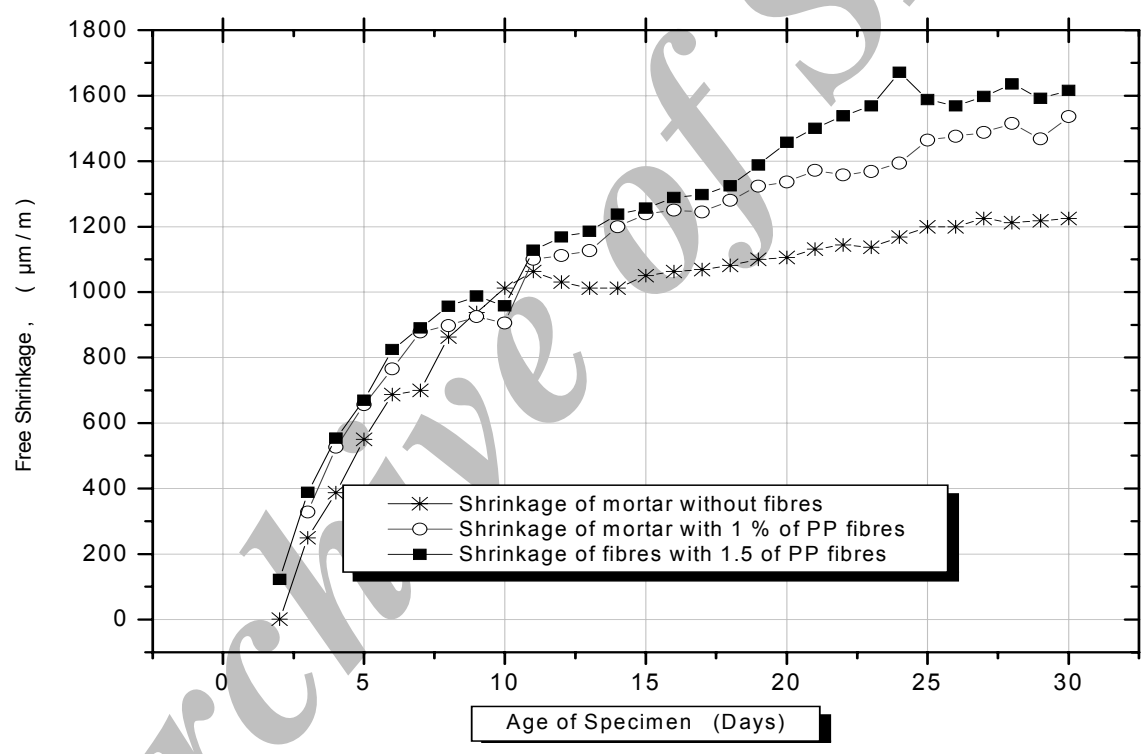

Figure 3. Free shrinkage of a mortar reinforces with polypropylene fibrous waste

\section{2. Restrained shrinkage}

The second part of the experimental programme was oriented towards the study of the effect caused by the introduction of fibre content on the cracking tendency of the mortar. The mixes of mortar were prepared with constant workability by using a superplasticizer in order to have always the same quantity of mixing water, and therefore the same water/cement ratio.

Cracking resistance of mortar was evaluated by the ring test. It was evaluated by the number of days and the thickness of the cracks. Figures 4 and 5 give an idea on the effect of the fibre addition in a cementing matrix like that of a mortar. In all the cases we observed a formation of 
macro-cracks with thickness varying between 0.6 to $0.8 \mathrm{~mm}$. Also, two deep macro-cracks on the fourth day have been remarked as seen in Figure 4.

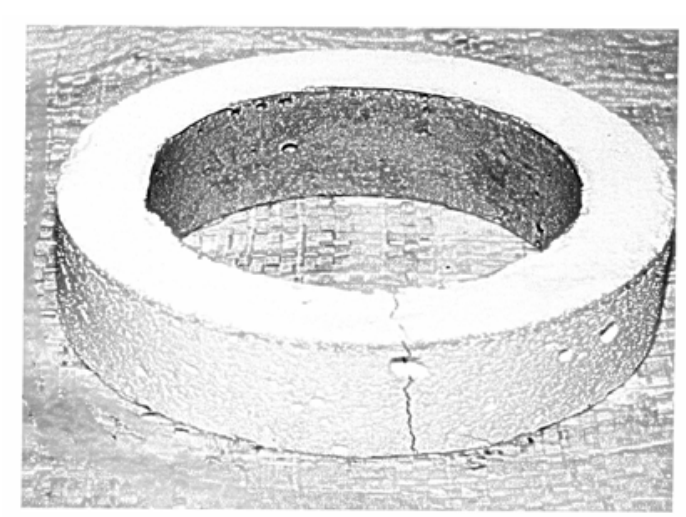

Figure 4 Appearance of the first macro-crack in a mortar without fibres

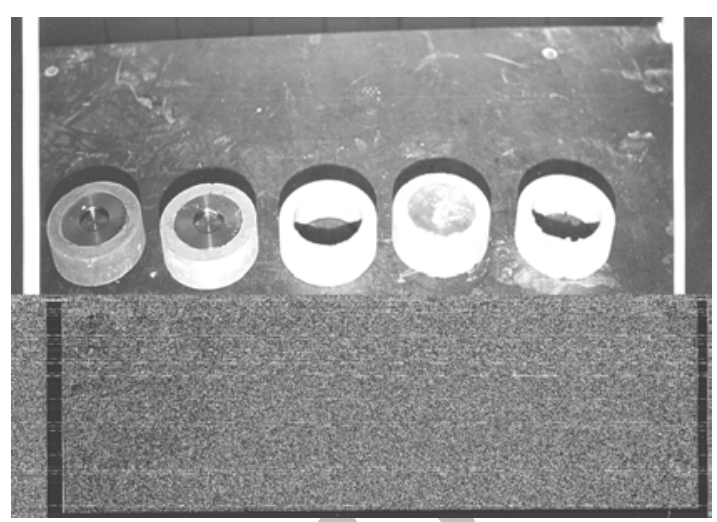

Figure 5 Mould with specimen and demoulded specimen for restrained shrinkage

But with $0.5 \%$ of steel fibres, microscopic cracks have been observed (seen with a magnifying glass) after 9 days. Whereas with a content of $1 \%$ of steel fibres the appearance of the microscopic cracks was not observed at early age less more than two weeks. By adding 1.5 $\%$ of steel fibres many microscopic cracks have been appeared after more than 4 weeks. The appeared cracks are very thick ( less than $0.1 \mathrm{~mm}$ ) and less deeper .

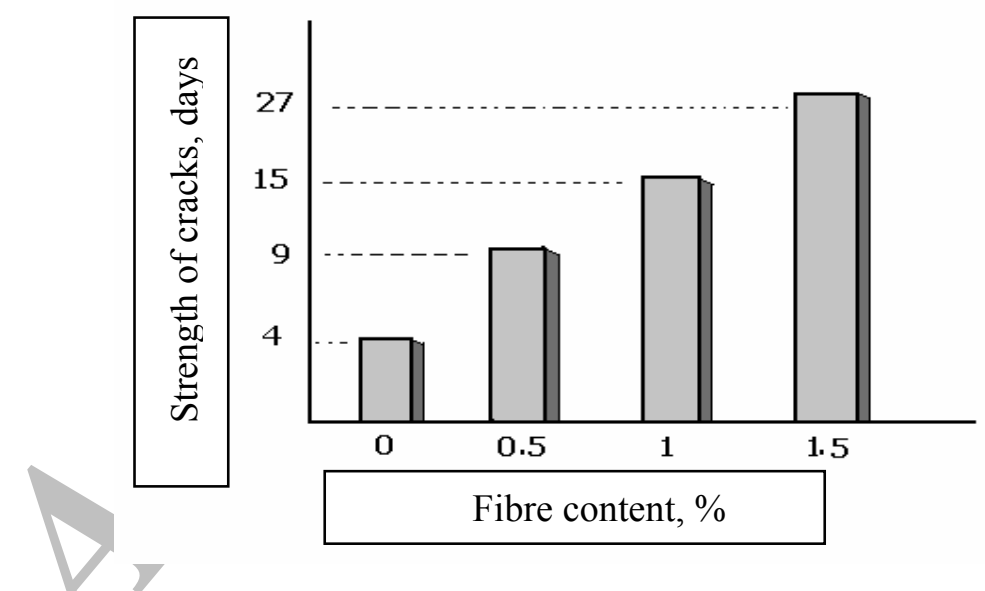

Figure 4 Cracking strength of mortar reinforced with steel fibres[0.5,1 and 1.5\%] 


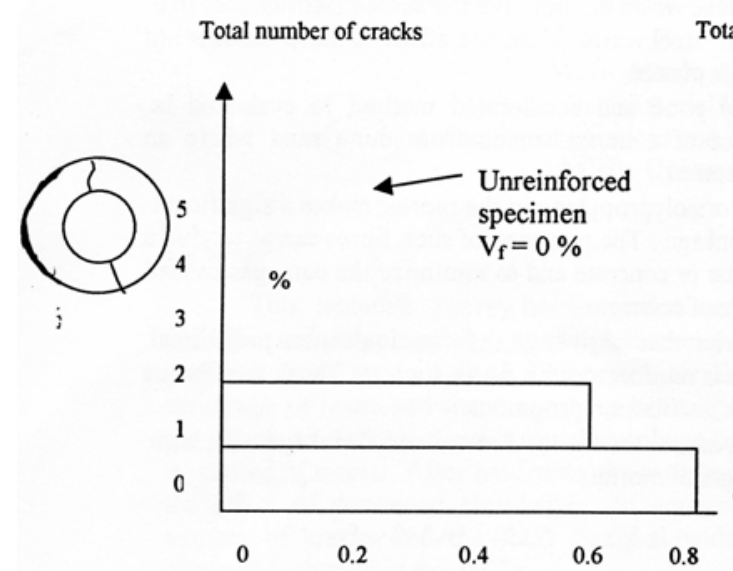

a) Crack width, $\mathrm{mm}$

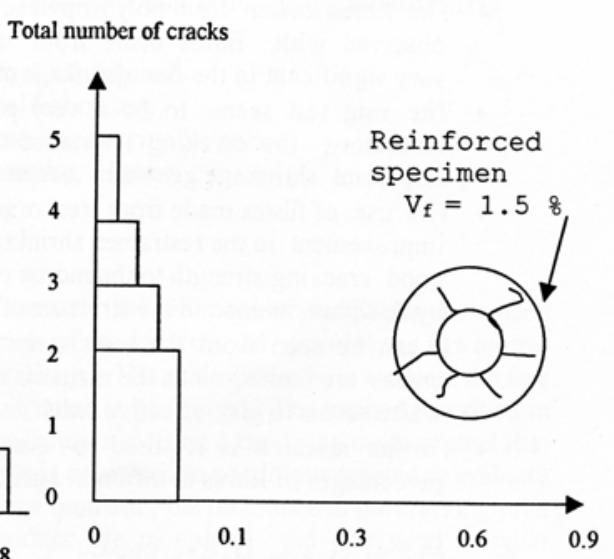

b) Crack width, $\mathrm{mm}$

Figure 5 Typical example from the tests showing the number of cracks, crack widths of unreinforced (a) and reinforced mortar with fibrous waste of polypropylene (b)

With the same mixture of mortar, specimens were prepared by adding polypropylene fibres. It is here that tests of restrained shrinkage (ring tests) were carried out by using percentages of fibres of 0.5 and $1 \%$. The observation from the test series confirm that the microscopic cracks in this kind of shrinkage did not appear before 4 weeks. This fact confirm also the results of a recent research [4] which shows that the introduction of fibre content equal or higher than $1 \%$ make in evidence that cracking processes is completely illuminated. The results obtained are illustrated in the table below:

Table 1 . The effect of polypropylene fibres on the restrained shrinkage

\begin{tabular}{|ccccccc|}
\hline N ${ }^{\circ}$ of mix & Cement & sand & Water & Admixture \% & Fibres & Cracking strength (days) \\
\hline \hline M01EP & 1 & 2 & 0.5 & 1 & $0 \%$ & Micro-cracks on 4 days \\
M02EP & 1 & 2 & 0.5 & 1.25 & $0.5 \%$ & No cracks after 35 days \\
M03EP & 1 & 2 & 0.5 & 1.75 & $1 \%$ & No cracks after 56 days \\
\hline
\end{tabular}

\section{CONCLUSION}

The following conclusions and recommendations are drawn from the present study:

- The use of fibres resulting from the industrial waste (steel or polypropylene) represents a profit in the promoting the use of wastes in civil engineering materials.

- The steel fibrous waste have made it possible to reduce the free phenomenon shrinkage by about $16 \%$ for a fibre content of $0.5 \%$. This reduction reaches at $13 \%$ for a fibres content 
of $1 \%$. However, beyond a content of $1.5 \%$ of fibres the no further improvement can be achliucd.

- The fibres made from polypropylene waste did not give the same performances observed with fibres made from steel waste. Thus, the effect of these fibres is not very significant in the free shrinkage matter.

- The ring test seems to be a very good and accelerated method to evaluate the cracking resistance of a mortar made from sand where an important shrinkage generally occurred.

- The use of fibres made from steel or polypropylene in the mortar makes a significant improvement in the restrained shrinkage. The presence of such fibres gives a good cracking strength to the mortar or concrete, minimizing the damages caused in the structure of concrete.

- It can be seen from the tests series that shrinkage deformation causes prejudicial cracks are limited when the matrix is reinforced with fibrous waste. Thus, the fibrous waste seems to give effective crack distribution properties.

- Further research is required to evaluate the free and restrained shrinkage with high percentages of fibres at different ages of mortar.

\section{REFERENCES}

1. Acker, P. Comportement mecanique du beton: Apports de l'approche physicochimique. Theese de Doctorat l'Ecole Nationale des Ponts et Chaussees, Paris. (1997).

2. MANGAT, P, S et AZARI, M.M. A theory of the free shrinkage of steel fibre reinforced cement matrices. Journal of Materials Sciences, Vol.19, N³, (1984) pp2183-2194.

3. SHAH, S.P; WEISS, J ET YANG, W. Shrinkage cracking can it be prevented. Magazine of the American Concrete Institute, (1998) pp.51-55.

4. Mesbah, H. A; Buyle, B.F et Siwak, J.M (1996). Influence de l'ajout des fibres sur le retrait des mortiers a base de granulats recycles. $2^{\mathrm{e}}$ Colloque International Francophone sur les betons renforces de fibres metalliques, Toulouse, pp163-172.

5. EDINGTON, J.; HANNANT, D. J; WILIAMS.R.I.T. Steel Fibre Reinforced Concrete; G. B. Building. Res. EST-Current paper, (1974) c.p.69/74 p - July 1974.

6. EL HACHEM, M. (1990). Eude de l'influence de la fibre de fonte sur le retrait et le fluage du beton. These de Doctorat, Ecole Centrale ,Paris.

7. Houari, H. Contribution a leude du comportement du beton renforce de fibres soumis al'action des charges maintenues et cycliques. Thèse de Doctorat, INSA Lyon,(1997).

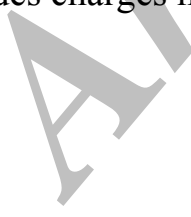




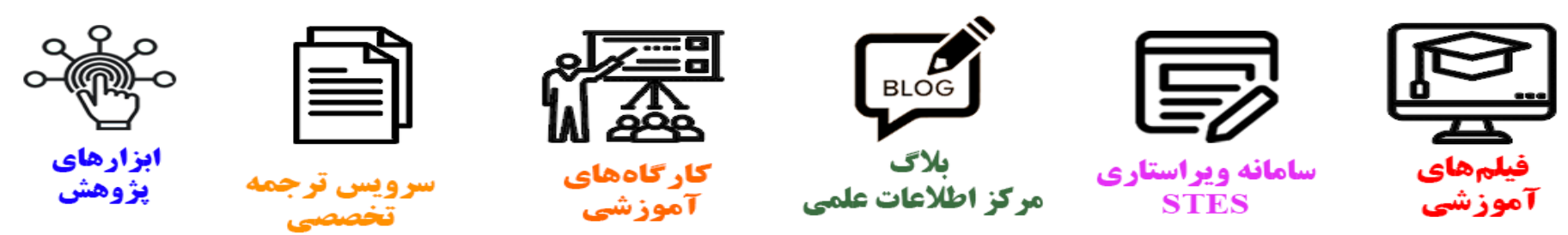

\section{(c)}

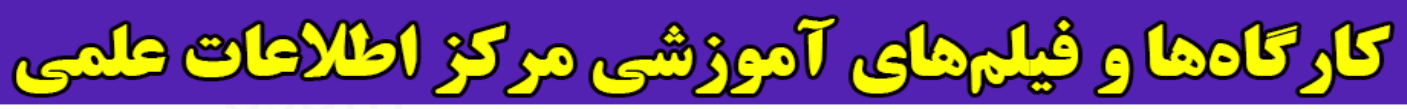
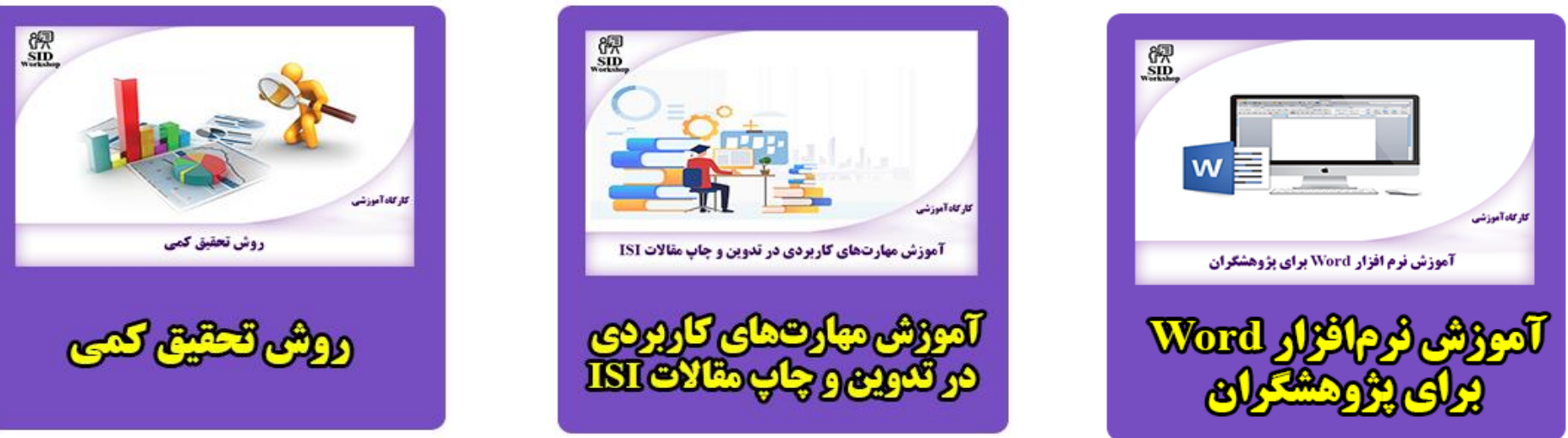